\title{
_Conference Reports
}

\author{
XVIIITH INTERNA'IIONAL MINERAL PROCESSING CONGRESS \\ 23 - 28 MAY 1993, SYDNEY
}

\begin{abstract}
Approximately six hundred delegates from over thirty countries attended the highly successful XVIIIth IMPC and accompanying exhibition of mineral processing equipment and design services. The congress consisted of a series of important review lectures which considered the current status of critical technologies (comminution, recycling, mineral colloids) and the problems of transferring new processing technology into industrial practice. For example, one of the key speakers, Mr. R. Mozley provided evidence that acceptance of new technologies is often driven by crises in plant operation or the international economy, rather than advance planning. This notion drew nods of agreement from the audience.
\end{abstract}

The technical sessions demonstrated that there was no shortage of innovative ideas and future opportunities for improving mineral processing technology. Approximately two hundred oral presentations were made in five parallel sessions. In the area of electrostatic and magnetic separation about nine papers appeared in the proceedings, viz.

Industrial applications of the high-intensity rare earth drum magnetic separator (D.A. Norrgran and R.A. Merwin)

Recovery of minus 100 micron hematite by wet high-intensity magnetic separation (D.J. Miller, D.G. James and J.H. Turner)

Magnetic separation in a flat OGMS with a multizone chamber (V.I. Boroz et al.)

The commercial application of the new two-stage Jones WHIMS process for martitic iron ores at Fabrica Mine of Ferteco Mineracao SA Brazil (H.Heep, T. Heyer and H.D. Wasmuth)

$A$ double drum separator for triboelectric separation of very fine materials ( $K$. Eichas and K. Schonert)

Commercial equipment designed to recover gold from gravitational concentrates by means of magnetic separation and separation in magnetic fluids (R.D. Smolkin, V.S. Krokhmal and O.P. Sayko)

Studies on new type of composed forces field separator (Yang Peng et al.)

A new type of continuous processing HGMS and its magnet system (Pimbo He et al.)

Electrostatic upgrading of phosphate ores (R. Ciccu et al.) 
Miller et al. described an interesting case study of the commissioning, operation and optimisation of WHIMS over a three year period for the recovery of fine hematite at BHP Iron Ore (Goldsworthy) Ltd. Laboratory and scale-up to plant design at a Brazilian hematite operation was also described by Heep et al., using two-stage WHIMS with different gap widths.

In a fascinating paper, Eichas and Schonert demonstrated how triboelectric methods could be extended to ultrafine particles $(1-100 \mu \mathrm{m})$ by introducing the feed effectively in the form of an aerosol and employing a double drum separator. The technique was demonstrated at a laboratory scale for binary mixtures (quartz/anthracite, quartz/barite, quartz/fluorite) of various sieve fractions. As might be anticipated, dealing with such fine materials presents some practical problems associated with agglomeration of the solids due to van der Waals forces. Nevertheless, the principle of the separation was demonstrated.

Ciccu et al. described the optimisation of a Turbocharger separator in the upgrading of Angolan phosphate ores, with a particular emphasis on the importance of target surface temperature $\left(100-150^{\circ}\right)$ on the charging of the ore minerals (phosphates, carbonate, quartz). Clearly, the potential economic benefits to be derived from dry processing are substantial. In this case it was concluded that the recoveries were 'fairly good' but evidently critically dependent on success of mineral liberation.

The full proceedings of the IMPC occupy some 1500 pages and are available in a five volume set from the Australasian Institute of Mining and Metallurgy, Clunies Ross House, 191 Royal Parade, Parkville, Victoria 3052, Australia. All the papers were refereed and are generally produced to an impressively high standard.

\author{
R.A. Williams \\ Department of Chemical Engineering \\ University of Manchester Institute of Science and Technology
}

\title{
A COURSE ON MAGNETIC SEPARATION TECHNOLOGY BRISBANE, AUSTRALIA, MAY 1993
}

A two-day course. entitled "Magnetic Separation Technology" was presented by Jan Svoboda from Magnetic Technology Consultants (Pty) Ltd., South Africa, to the members of the mineral processing industry. The course was hosted by the Julius Kruttschnitt Mineral Research Centre, University of Queensland, in Brisbane, Australia.

Those who attended included metallurgists, technicians, electricians and physicists. The course was aimed to reduce the knowledge barriers that exist between engineers and physicists. The course content was clearly presented so that all could benefit from Jan's theoretical knowledge and experience. 
The programme included a particularly interesting session on the fundamental physics of magnetic separation. Those within the mineral processing industry are rarely exposed to the underlying physics behind their magnetic separators. The design, application, optimisation and economics of various magnetic separation techniques were discussed in detail. Particular reference was made to the recent advances in high-gradient magnetic separators.

This well presented course provided a wealth of information to those fortunate enough to attend. The only real criticism would be the lack of a similar course on electrostatic separation.

N. Linton

RGC Mineral Sands Ltd.

Geraldton, Australia 